\title{
ANÁLISE COMPARATIVA DO CUSTO-BENEFÍCIO ENTRE PAVIMENTAÇÃO ASFÁLTICA E A COM BLOCOS INTERTRAVADOS DE CONCRETO
}

\section{COMPARATIVE COST-BENEFIT ANALYSIS BETWEEN ASPHALT PAVING AND BLOCKS CONCRETE INTERLOCKED}

\author{
Vinicius Almeida de Barros \\ Graduando, Faculdade Presidente Antônio \\ Carlos, Brasil. E-mail: \\ viniciussalmeidaa13@gmail.com \\ Jose Alves Pereira Neto \\ Graduando, Faculdade Presidente Antônio \\ Carlos, Brasil. E-mail: neto.joseap@gmail.com \\ Augusto Petzold \\ Mestre, Faculdade Presidente Antônio Carlos, \\ Brasil. E-mail: augustopetzold2014@gmail.com
}

Recebido: 20/05/2021 - Aceito: 20/05/2021

\section{RESUMO}

Este trabalho tem como objetivo comparar economicamente o pavimento asfáltico executado no sistema viário do "Empreendimento Macatuba" localizado na cidade de Macatuba-SP e o pavimento intertravado como alternativa de pavimentação. Durante a revisão da literatura buscou-se a descrição do processo de pavimentação, referencial histórico, assim como, seu processo executivo, dando ênfase aos conceitos associados a pavimentos intertravados e os pavimentos asfálticos, destacando suas vantagens e desvantagens em relação à escolha do melhor tipo de pavimento viário. Foi dimensionado o pavimento intertravado e realizado a comparação estrutural com o pavimento asfáltico. De posse dos quantitativos obtidos das estruturas dos dois pavimentos foram elaborados os respectivos orçamentos através da tabela SINAPI para a comparação dos custos. Ao final, coloca-se a partir dos resultados alcançados no trabalho, a viabilidade técnica e econômica da implantação do bloco intertravado como solução ao sistema viário do objeto de estudo.

Palavras-chave: Pavimentação; Bloco Intertravado; Pavimento Asfáltico; Sinapi; Comparativo. 


\section{ABSTRACT}

This work aims to economically compare the asphalt pavement executed in the road system of the "Macatuba Enterprise" located in the city of Macatuba-SP and the pavement interlocked as a paving alternative. During the literature review, we sought the description of the paving process, historical reference, as well as its executive process, emphasizing the concepts associated with interlocked pavements and asphalt pavements, highlighting its advantages and disadvantages in relation to the choice of the best type of road pavement. The interlocked floor was dimensioned and a structural comparison was made with the asphalt pavement. In possession of the quantitative obtained from the structures of the two floors, the respective budgets were prepared through the SINAPI table for the comparison of costs. At the end, it is based on the results achieved in the work, the technical and economic feasibility of the implementation of the block interlocked as a solution to the road system of the object of study.

Keywords: Paving; Interlocked block; Asphalt Pavement; Sinapi; Comparative.

\section{INTRODUÇÃO}

No Brasil o transporte rodoviario é sem duvidas a principal alternativa para movimentação de cargas e pessoas, contribuindo de forma significativa para o desenvolvimento socioeconômico nacional.

Segundo a Confederação Nacional de Transportes CNT (2019), a densidade da malha rodoviária pavimentada do Brasil corresponde a apenas $12,4 \%$ da extensão rodoviária nacional, que são equivalentes a $213.453 \mathrm{Km}$ de vias pavimentadas.

O pavimento é constituído por camadas de diferentes materiais de forma a fornecer segurança e conforto aos usuários. Existem no mercado diferentes tipos de pavimentos: rígido, semirrígido e flexível.

A grande variedade de materiais utilizados na construção civil é oriunda de fontes renováveis e de fontes não renováveis. Somente os materiais provenientes de fontes renováveis são considerados sustentáveis em termos construtivos, para a atual e para a futura geração. O conceito de sustentabilidade, de reciclagem e de ciclo de vida dos materiais é de extrema importância para minimizar os 
Revista Multidisciplinar do Nordeste Mineiro, v.2 2021/02

ISSN 2178-6925

problemas ambientais. 
Segundo a Associação Brasileira de Cimento Portland (2019) o pavimento rígido é mais durável e tem menor necessidade de intervenções de manutenção durante seu ciclo de vida se comparado ao pavimento flexível que pode apresentar vantagem no custo inicial de construção. Porém com o aumento de mais de $60 \%$ nos custos dos ligantes asfálticos no último ano, além do novo método de dimensionamento de pavimentos asfálticos esse panorama pode ter mudado. Nessas condições os pavimentos asfálticos acabam ficando bem mais caros, tornado seu uso inviável economicamente e favorecendo a utilização de pavimentos rígidos de concreto.

Esse cenário justifica a importância de se estudar este assunto, e mais ainda, promover análises que viabilizem a economia na execução deste tipo de infraestrutura em vias urbanas. Além disso, atiça o estudo do emprego de outras tecnologias de pavimentação, como uma alternativa ao pavimento asfáltico.

Este trabalho tem como objetivo fazer uma comparação entre o custo final dos dois tipos de revestimentos de pavimentos, abrangendo a execução, a conservação e a manutenção das camadas de revestimentos.

A pavimentação com blocos intertravados de concreto, para efeito deste trabalho, foi analisada como uma solução alternativa entre os pavimentos flexíveis asfálticos, quando a aplicação desses se tornar inviável, seja por motivos técnicos, seja por motivos econômicos..

\section{OBJETIVOS}

O objetivo geral do trabalho é dimensionar o pavimento viário de um conjunto habitacional, utilizando a tecnologia de artefatos de cimento intertravados, e comparar com o dimensionamento do pavimento asfáltico executado no projeto, bem como, comparar técnico e economicamente a viabilidade de implantação de ambas.

Para atingir o objetivo geral, foram definidos os seguintes objetivos específicos:

a) Analisar o projeto e o dimensionamento do pavimento asfáltico utilizado pela contratada para a execução da obra;

b) Realizar o levantamento do custo de execução do piso intertravado por meio de banco de dados;

c) Realizar o estudo comparativo entre o projeto do pavimento intertravado e 
Revista Multidisciplinar do Nordeste Mineiro, v.2 2021/02

ISSN 2178-6925

o pavimento asfáltico. 


\section{REVISÃO DE LITERATURA}

Existe no ser humano a busca incansável pela melhoria pessoal e coletiva na forma de viver, com a expansão natural da população, percebeu-se que as vias de acesso entre os povos necessitavam de um aprimoramento para alocomoção, assim surgiram os precedentes dos calçamentos, onde, o solo inalterado recebeu blocos de rochas. Estudos apontam que já existiam pavimentos em forma calçamento há mais de 2.000 anos AC no Antigo Egito, como exemplo apontam a suntuosa Estrada de Elefantina.

De acordo com Knapton (1996), os romanos foram os precedentes na aplicação da Mecânica dos Solos na implantação de estradas. O vocábulo calçada tinha como sinônimo via romana, definição essa para via calçada de pedra, no presente, o termo calçada é empregado normalmente ao local de circulação de pedestres (Santana, 1993).

O proposito exemplar da pavimentação em vias era aperfeiçoar o deslocamento sob toda condição climática, isto em localidades com baixa circulação de veículos pesados e com moderado número de pessoas. Em parte, lugares com elevado tráfego e densidade populacional elevada, o papel fundamental da pavimentação terá de ser o dimensionamento estrutural (Oliveira, 2018).

Dessa forma, Senço (2007) apresenta que o pavimento é a infraestrutura arquitetada sobre a terraplanagem com destinação técnica e econômica devendo, suportar e compartilhar as forças verticais originários do trafego, aperfeiçoar as circunstâncias de rolagem no que se refere ao conforto e seguridade e, suportar as forças horizontais fazendo assim as vias mais duradouras.

O pavimento de uma via é uma estrutura formada por conjuntos de camadas de densidades finitas, assentado acima de um plano julgado hipoteticamente como infinito DNIT (2006a). Segundo Bernucci et al. (2007) o modo estrutural sujeita-se da densidade de cada uma das camadas, da solidez das mesmas e do subleito, assim como da relação entre as divergentes camadas do pavimento, sendo eles, formados fundamentalmente pelas camadas: subleito, reforço do subleito, quando necessário, sub-base, base e revestimento (Augusto Junior, 1992). Os revestimentos conforme a figura 01. 
Revista Multidisciplinar do Nordeste Mineiro, v.2 $2021 / 02$

ISSN 2178-6925

Figura 01: Composição de pavimentação

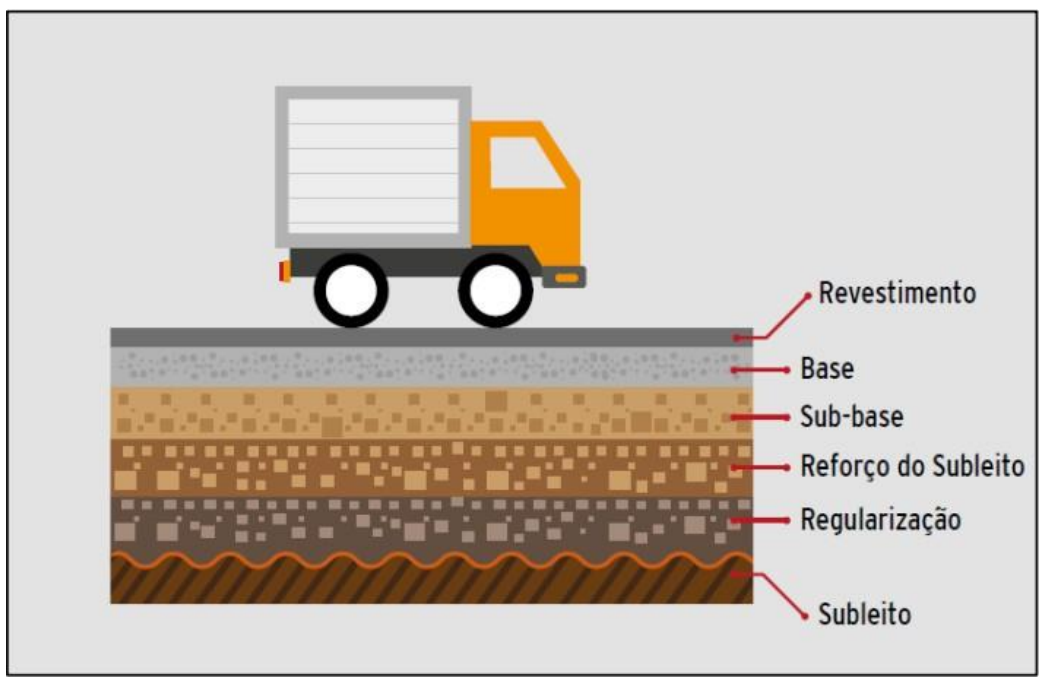

Fonte: CNT (2016)

Apontado as quatro principais camadas da pavimentação (subleito, sub-base, base e revestimento) podemos entender como cada uma age e qual sua utilização/função:

\section{- SUBLEITO}

Essa camada é o resultado do estudo da topografia e terraplanagem no local, ela a finalização que irá receber o tipo de pavimento desejado. Ela deva ser regulare completamente compactada de acordo com a cota necessária. Este pano fica em condições de admitir outras camadas quando o Índice de Suporte California (CBR) for maior ou igual a $2 \%$, e que, a expansão volumétrica for menor ou igual a $2 \%$. Caso não respeite o $\mathrm{CBR}$, deverá conter o reforço do subleito como apontado na Associação Brasileira de Normas Técnicas (ABNT, 2011). O reforço por sua vez, deverá atender a NBR 12752, onde é sugerido pelo Carvalho (1998) apud Filgueiras (2019) que, o pano deverá ter no mínimo 30 centímetros de espessura e respeitar o CBR 5 pontos acima do encontrado no subleito. Pode-se também fazer a substituição do material contido na camada do subleito, assim respeitando os pontos anteriores.

\section{- SUB-BASE}

Alguns autores como Shackel (1991 apud Cruz, 2003), apontam que a subbase deverá ser executada quando houver necessidade, seu exercício é semelhante ao próximo ponto, a base, visa ampliar a resistência geral da estrutura. Ela está diretamente ligada a onda de tráfego nas vias.

- BASE 
Esse pano é destinado a obter os esforços em que o revestimento recebe das vias e o dividir sem que impacte diretamente o subleito, assim certificando seu estado estável. Normalmente é produzido com misturas estabilizadas com cimento e/ou petróleo, podendo formar uma base impermeável e com resistência mecânica concebível. De acordo com ABCP (2010), deve-se ter uma camada de no mínimo 10 centímetros.

\section{- REVESTIMENTO}

O revestimento é o último ponto da via, onde será recebido a movimentação e esforços do tráfego necessário. Pode ser escolhido de acordo com utilização necessária, custo ou mão de obra.

Segundo DNIT (2016), os pavimentos podem ser definidos como flexíveis, semirrígidos e rígido, onde, os pavimentos flexíveis permitem a deformidade quando a um carregamento aplicado, as forças se distribuem em fragmentos quase igualitários entre as camadas, temos como exemplo o pavimento formado por base de brita ou solo pedregulhoso, revestido por uma camada asfáltica. Já o semirrígido é identificado pelo revestimento asfáltico por uma base/sub-base tendo adição de cimento, como exemplo podemos apontar uma camada de solo cimento revestida por uma camada asfáltica, sua deformabilidade está entre o rígido e flexível. Alguns autores banem a utilização da condição semirrígido por apenas existir traços de base cimentada, assim utilizando apenas rígido ou flexível. O pavimento rígido tem como característica a absorção das forças aplicadas sobre ele, já que, sua rijeza é maior que as camadas abaixo do revestimento. Como exemplo temos o pavimento intertravado, constituído por blocos de concreto.

Levando em consideração os tipos de pavimentos, para a comparação do atual trabalho, será estudado a pavimentação flexível tendo como base a pavimentação asfáltica e a pavimentação rígida com base a pavimentação de bloco intertravado.

\subsection{PAVIMENTAÇÃO ASFÁLTICA.}

Os pavimentos asfálticos, são compostos por uma camada de rolagem continua, denominada concreto asfáltico, não é realizada qualquer junção e sua espessura deve ser realizada conforme o tráfego daquele local. Suas camadas são normalmente constituídas de acordo com a Figura 02. De acordo com o tráfego, uma ou mais camadas podem ser acrescidas ou eliminadas (Bernucci et al., 2007). 
Revista Multidisciplinar do Nordeste Mineiro, v.2 $2021 / 02$

ISSN 2178-6925

Figura 02: Pavimento de concreto asfáltico.

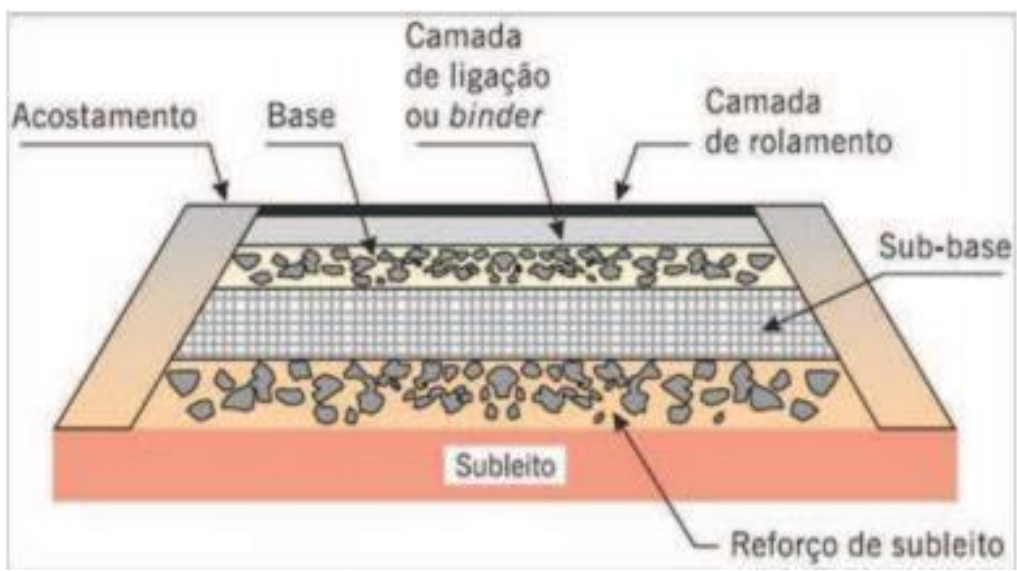

Fonte: Bernucci et al. (2007)

De acordo com Bernucci et al. (2007), o asfalto utilizado para a camada de rolagem é um ligante betuminoso, proveniente da destilação do petróleo com especificidade impermeável e pouco reativo. Na maior parte de países no mundo, a pavimentação asfáltica é a primeira a ser escolhida, o Brasil não fica para fora da estatística, aproximadamente $95 \%$ das vias, sendo elas rodovias ou ruas, a pavimentadas dispõem de revestimento asfáltico.

Segundo Nakamura (2011), o CBUQ (Concreto Betuminoso Usinado a Quente) segue como principal opção para a execução. Nada mais é que o resultado da combinação de agregados de várias dimensões e cimento asfáltico, ambos são aquecidos em conjunto a uma determinada temperatura, formando o CAP (Cimento Asfáltico de Petróleo), conhecido como o asfalto convencional.

A utilização do asfalto nas pavimentações tem-se por meio de incontáveis razões, podemos apontar como exemplo o fato dele possibilitar uma grande fusão dos agregados que o constitui, admitindo uma maleabilidade até certo ponto do pavimento, ter uma boa vida útil e ser impermeável.

\subsection{PAVIMENTO INTERTRAVADO DE CONCRETO.}

A estruturação do pavimento intertravado é descrito como blocos com melhor resistência e longevidade, onde são assentados sobre uma cama de areia e, camadas subsequentes: base, sub-base e subleito. Os blocos e a camada de assentamento são retidos pelo flanco e o próprio atrito entre elas (Wiebbeling, 2015).

De acordo com Ferreira (2011), uma das principais escolhas para a pavimentação utilizando intertravados é a elevada durabilidade, sua face plana e antiderrapante e, por sua estrutura ter uma cor mais clara temos uma redução nas 
despesas com iluminação pública. Podemos citar também a permeabilidade das vias, fazendo com que a água da superfície regresse aos lençóis freáticos.

A densidade de aplicação de cada camada do pavimento intertravado será executada da mesma forma que a pavimentação asfáltica, deverá ser analisado o tráfego da via, o estudo da tipologia do solo e as especificidades de cada camada pressuposta (ABCP, 1999 apud Oliveira, 2018).

Figura 03: Estruturação de pavimentação do bloco de concreto intertravado.

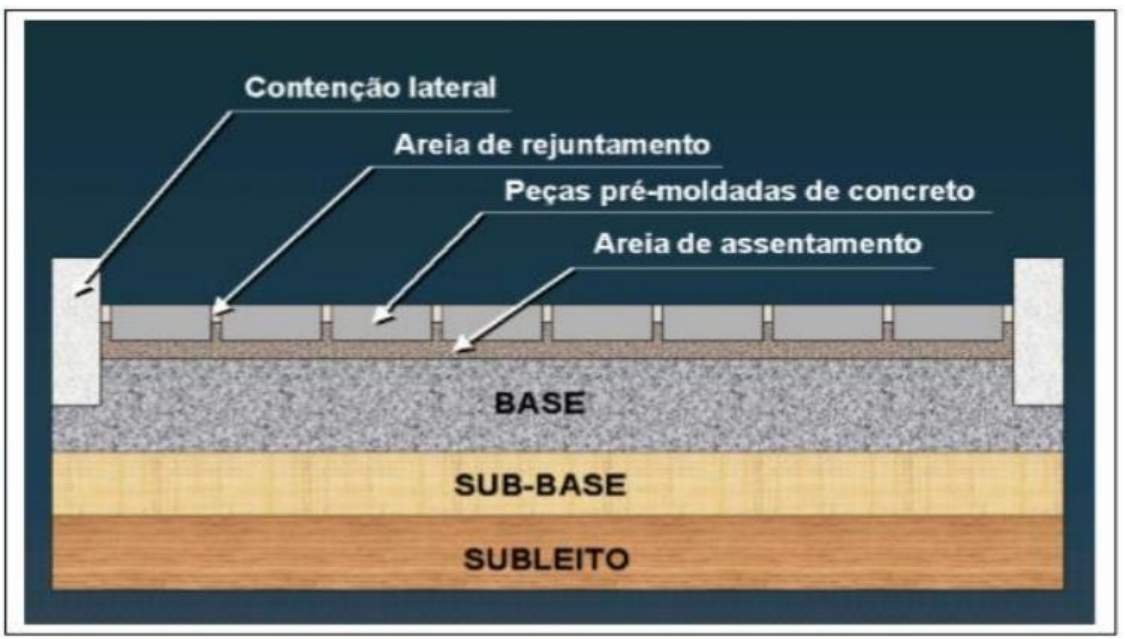

Fonte: $A B C P(1999)$

Os blocos intertravados possuem uma grande diversidade de formas, podendo garantir assim diversas disposições de acordo com o local de aplicabilidade.

Figura 04: Tipos de bloco intertravado.

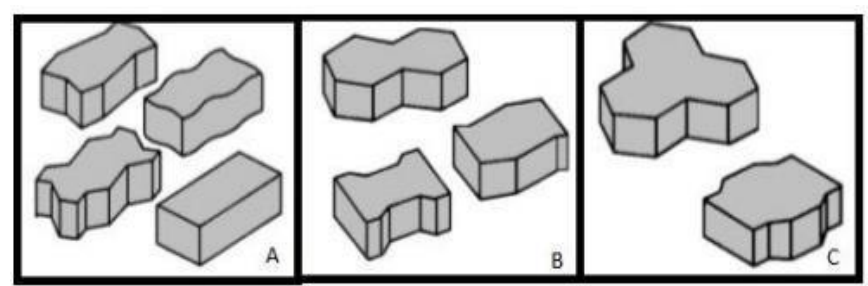

Fonte: Adaptado SCHACKEL ,1990 apud GODINHO 2009

Assim como seus formatos, os blocos intertravados podem ser assentados em algumas formas, fazendo assim com que consigam suportar a movimentação do deslocamento de cada peça, sendo ele horizontal, vertical, transversal ou até mesmo rotacional. (ABCP, 2010) 
Figura 05: Padrões de assentamento

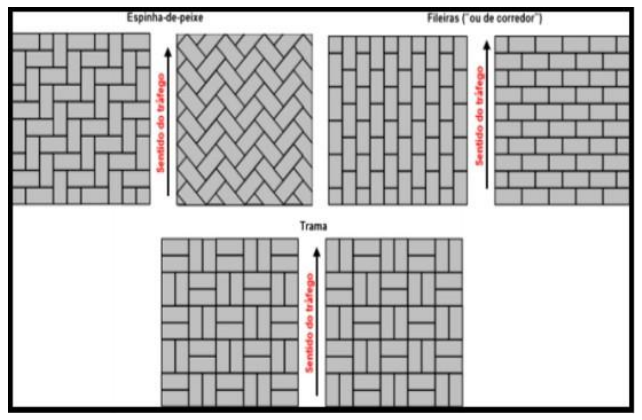

Fonte: Adaptação HALLACK, 1999

Quando necessário a manutenção dos pavimentos intertravados, Carvalho (1998) aponta que, geralmente ocorre a ausência do reforço da fundação estrutural, dessa maneira, deve-se trocar os blocos e o seu rejuntamento, aplicando também esses cuidados as camadas inferiores para que não ocorra o mesmo desgaste no ponto reconstruído.

Dito isso, Muller (2005) prevê que as vias com blocos intertravados tem como principal vantagem sobre os pavimentos asfálticos sua manutenção, pois, sua simplicidade na execução pode ser de forma direta ao ponto que necessita ser restaurado.

\section{METODOLOGIA}

Como um todo, a construção civil apresenta índices de baixa produtividade e alto desperdício. Este desperdício juntamente com outros problemas pode vir a ser evitados e/ou amenizados através de um bom planejamento orçamentário.

Orçamentos são previsões de custo dos produtos ou serviços com condições necessárias para a realização dos mesmos. Para se realizar um Orçamento de Obra é necessário, primeiramente, que seja feito todo o levantamento dos insumos e da mão de obra necessários, posteriormente, deve-se realizar uma pesquisa de preços no mercado para que seja possível quantificar o custo unitário de cada item orçado, por fim, deve ser calculado a carga tributária sobre a mão de obra necessária e o custo total de cada etapa da obra.

Para a realização deste trabalho foram utilizados orçamentos com base na tabela do SINAPI (Sistema Nacional de Pesquisa de Custos e Índices da Construção Civil) com referência em composições de Julho/2020, tabela muito utilizada para orçamento de obras. Na tabela SINAPI são apresentadas as composições de serviços 
Revista Multidisciplinar do Nordeste Mineiro, v.2 $2021 / 02$

ISSN 2178-6925

a serem utilizadas nos orçamentos de obras realizados por engenheiros e arquitetos. 
As tabelas SINAPI apresentam um descritivo detalhado dos insumos e da mão de obra necessária para a execução dos serviços.

No presente trabalho será analisado um estudo de caso no Empreendimento Macatuba (Imagem 6). Esse empreendimento está situado na Rua João Carlos Helub, Jardim Esperança - Macatuba-SP. Esse empreendimento é formado por 162 lotes, onde foram construídas 162 unidades habitacionais (Casas Populares), possui área total de $79.117,65 \mathrm{~m}^{2}$ e $32.400,56 \mathrm{~m}^{2}$ de área construída, sendo $17.013,41 \mathrm{~m}^{2}$ de pavimento viário executado.

Figura 03: Empreendimento Macatuba (Vista Aérea)

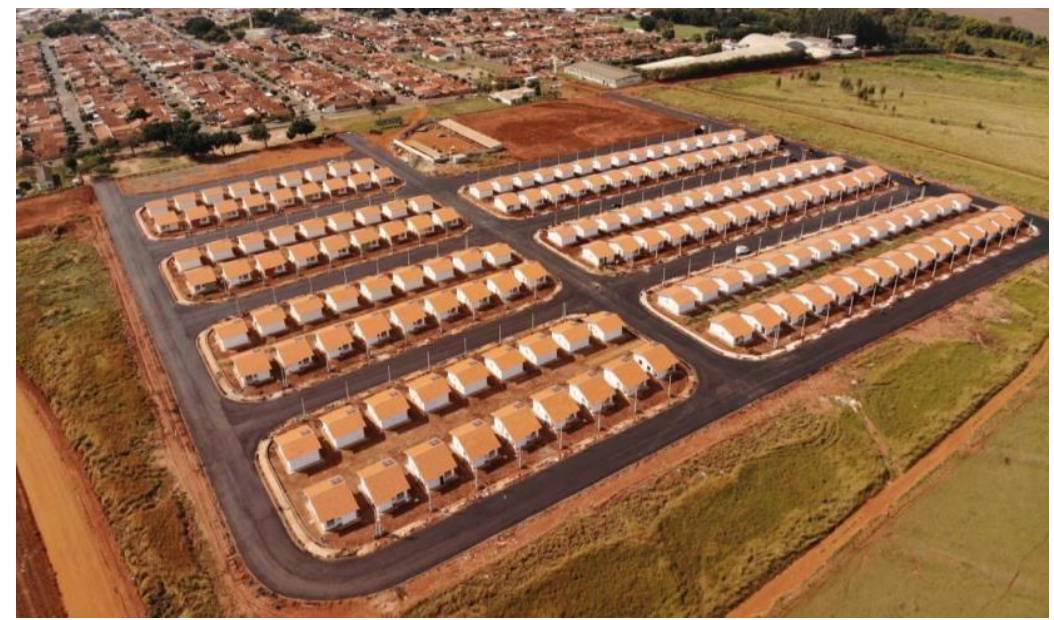

Fonte: Autoria Própria

A escolha por este empreendimento em específico se deu pois o mesmo foi executado em terreno plano sem a presença de grandes elevações, o que permitiu que fosse feita uma análise mais detalhada no quesito da comparação dos dois tipos de pavimento analisados. Também foi levado em consideração a tipologia da obra, visto que por ser um empreendimento de cunho Social, (Casas Populares), a análise do custo-benefício poderá servir para reduzir de melhor forma o gasto do projeto.

Como é visto na Figura 6 acima, todo o pavimento viário do empreendimento já se encontra executado. Toda a pavimentação foi realizada em Concreto Betuminoso Usinado a Quente (CBUQ), por motivos de sigilo por parte da empresa contratada para a execução do empreendimento, não se foi possível ter acesso aos valores realizados para a execução do mesmo, sendo fornecido apenas o projeto e o dimensionamento do pavimento asfáltico utilizado pela contratada.

Como informado anteriormente, foi utilizada a tabela SINAPI para a obtenção dos serviços e valores para a realização do comparativo entre os tipos de pavimentos. 
Na tabela 1 temos a presença de todos os insumos, serviços e valores unitários necessários para a execução da pavimentação em CBUQ:

Tabela 1: Composição de Execução de Pavimento com Aplicação de Concreto Asfáltico, Camada de Rolamento - Exclusive Carga e Transporte. (AF_11/2019)

\begin{tabular}{|c|c|c|c|c|c|c|}
\hline Código & Serviço & Unidade & Coeficiente & & \multirow{4}{*}{22,86} & \multirow[t]{4}{*}{ Total } \\
\hline 1518 & $\begin{array}{l}\text { CONCRETO BETUMINOSO USINADO A QUENTE (CBUQ) PARA PAVIMENTACAO } \\
\text { ASFALTICA, PADRAO DNIT, FAIXA C, COM CAP 50/70 - AQUISICAO POSTO USINA }\end{array}$ & $\mathrm{T}$ & 2,5548 & $\mathrm{R} \$$ & & \\
\hline 5835 & $\begin{array}{l}\text { VIBROACABADORA DE ASFALTO SOBRE ESTEIRAS, LARGURA DE PAVIMENTAÇÃO } \\
\text { 1,90 M A 5,30 M, POTÊNCIA } 105 \text { HP CAPACIDADE } 450 \text { T/H - CHP DIURNO. AF_11/2014 }\end{array}$ & $\mathrm{CHP}$ & 0,0464 & $\mathrm{R} \$$ & & \\
\hline 5837 & $\begin{array}{l}\text { VIBROACABADORA DE ASFALTO SOBRE ESTEIRAS, LARGURA DE PAVIMENTAÇÃO } \\
\text { 1,90 M A 5,30 M, POTÊNCIA } 105 \text { HP CAPACIDADE } 450 \text { T/H - CHI DIURNO. AF_11/2014 }\end{array}$ & $\mathrm{CHI}$ & 0 & & & \\
\hline 88314 & $\begin{array}{l}\text { RASTELEIRO COM ENCARGOS COMPLEMENTARES } \\
\text { CAMINHÃO BASCULANTE } 10 \mathrm{M} 3 \text {, TRUCADO CABINE SIMPLES, PESO BRUTOTOTAL }\end{array}$ & $\mathrm{H}$ & & & & \\
\hline 91386 & $\begin{array}{l}23.000 \mathrm{KG} \text {, CARGA ÚTIL MÁXIMA } 15.935 \mathrm{KG} \text {, DISTÂNCIA ENTRE EIXOS } 4,80 \mathrm{M} \text {, } \\
\text { POTÊNCIA } 230 \text { CV INCLUSIVE CACCAMBA METÁLICA - CHP DIURNO. AF_06/2014 } \\
\text { ROLO COMPACTADOR VIBRATORIO TANDEM, ACO LISO, POTENCIA 125 HP }\end{array}$ & & & & & \\
\hline 95631 & $\begin{array}{l}\text { SEM/COM LASTRO 10,20/11,65 T, LARGURA DE TRABALHO } 1,73 \mathrm{M}-\mathrm{CH} \\
\text { AF_11/2016 } \\
\text { ROLO COMPACTADOR VIBRATORIO TANDEM, ACO LISO, PO }\end{array}$ & & & & & \\
\hline 95632 & $\begin{array}{l}\text { SEM/COM LASTRO 10,20/11,65 T, LARGURA DE TRABA } \\
\text { AF_11/2016 }\end{array}$ & & & & & \\
\hline 96155 & $\begin{array}{l}\text { TRATOR DE PNEUS COM POTÊNCIA DE } 85 \text { C } \\
\text { MECÂNICA ACOPLADA - CHI DIURNO. A }\end{array}$ & & & & & \\
\hline 96157 & $\begin{array}{l}\text { TRATOR DE PNEUS COM POTÊNC } \\
\text { MECÂNICA ACOPLADA - CH }\end{array}$ & & & & & \\
\hline 96463 & $\begin{array}{l}\text { ROLO COMPACTADO } \\
\text { HP, PESO SEM/ } \\
\text { DIURNO. AF }\end{array}$ & & & & & \\
\hline 96464 & ROL & & & & & \\
\hline
\end{tabular}

Fonte: SINAPI

A tabela 2 fornece os insumos, serviços e valores unitários necessários para a execução da pavimentação com blocos intertravados de concreto:

Tabela 2: Composição de Execução de Via em Piso Intertravado, Com Bloco 16 Faces de 22 X 11 CM, Espessura 8 CM. (AF_12/2015)

\begin{tabular}{|c|c|c|c|c|c|c|c|}
\hline \multirow{2}{*}{ Código } & \multirow{2}{*}{$\begin{array}{l}\text { Serviço } \\
\text { AREIA MEDIA - POSTO JAZIDA/FORNECEDOR (RETIRADO NA JAZIDA, SEM } \\
\text { TRANSPORTE) }\end{array}$} & \multirow{2}{*}{$\begin{array}{c}\text { Unidade } \\
\text { M3 }\end{array}$} & \multirow{2}{*}{$\begin{array}{c}\text { Coeficiente } \\
0,0568\end{array}$} & \multicolumn{2}{|c|}{$\begin{array}{c}\text { Valor } \\
\text { Unitário }\end{array}$} & \multicolumn{2}{|c|}{ Total } \\
\hline & & & & $\mathrm{R} \$$ & 52,48 & $\mathrm{R} \$$ & 2,98 \\
\hline 4741 & PO DE PEDRA (POSTO PEDREIRA/FORNECEDOR, SEM FRETE) & M3 & 0,0085 & $\mathrm{R} \$$ & 50,87 & $\mathrm{R} \$$ & 0,43 \\
\hline 36170 & $\begin{array}{l}\text { BLOQUETE/PISO INTERTRAVADO DE CONCRETO - MODELO ONDA/16 } \\
\text { FACES/RETANGULAR/TIJOLINHO/PAVER/HOLANDES/PARALELEPIPEDO, *22 CM X } \\
11^{*} \mathrm{CM}, \mathrm{E}=8 \mathrm{CM}, \mathrm{RESISTENCIA} \mathrm{DE} 35 \mathrm{MPA} \text { (NBR 9781), COR NATURAL }\end{array}$ & M2 & 1,0144 & $\mathrm{R} \$$ & 42,00 & $\mathrm{R} \$$ & 42,60 \\
\hline 88260 & CALCETEIRO COMENCARGOS COMPLEMENTARES & $\mathrm{H}$ & 0,3080 & $\mathrm{R} \$$ & 24,12 & $\mathrm{R} \$$ & 7,43 \\
\hline 88316 & SERVENTE COM ENCARGOS COMPLEMENTARES & $\mathrm{H}$ & 0,3080 & $\mathrm{R} \$$ & 20,42 & $\mathrm{R} \$$ & 6,29 \\
\hline 91277 & $\begin{array}{l}\text { PLACA VIBRATÓRIA REVERSIVEL COM MOTOR } 4 \text { TEMPOS A GASOLINA, FORÇA } \\
\text { CENTRÍFUGA DE } 25 \mathrm{KN} \text { (2500 KGF), POTÊNCIA 5,5 CV - CHP DIURNO. AF_08/2015 }\end{array}$ & $\mathrm{CHP}$ & 0,0055 & $\mathrm{R} \$$ & 6,40 & $\mathrm{R} \$$ & 0,04 \\
\hline 91278 & $\begin{array}{l}\text { PLACA VIBRATÓRIA REVERSÍVEL COM MOTOR } 4 \text { TEMPOS A GASOLINA, FORÇA } \\
\text { CENTRÍFUGA DE } 25 \text { KN ( } 2500 \text { KGF), POTÊNCIA 5,5 CV - CHI DIURNO. AF_08/2015 }\end{array}$ & $\mathrm{CHI}$ & 0,1485 & $\mathrm{R} \$$ & 0,38 & $\mathrm{R} \$$ & 0,06 \\
\hline 91283 & $\begin{array}{l}\text { CORTADORA DE PISO COM MOTOR } 4 \text { TEMPOS A GASOLINA, POTÊNCIA DE } 13 \text { HP, } \\
\text { COM DISCO DE CORTE DIAMANTADO SEGMENTADO PARA CONCRETO, DIÂMETRO } \\
\text { DE } 350 \mathrm{MM}, \text { FURO DE 1" (14 X 1") - CHP DIURNO. AF_08/2015 }\end{array}$ & $\mathrm{CHP}$ & 0,0135 & $\mathrm{R} \$$ & 14,92 & $\mathrm{R} \$$ & 0,20 \\
\hline 91285 & $\begin{array}{l}\text { CORTADORA DE PISO COM MOTOR } 4 \text { TEMPOS A GASOLINA, POTÊNCIA DE } 13 \text { HP, } \\
\text { COM DISCO DE CORTE DIAMANTADO SEGMENTADO PARA CONCRETO, DIÂMETRO } \\
\text { DE } 350 \text { MM, FURO DE 1" (14 X 1") - CHIDIURNO. AF_08/2015 }\end{array}$ & $\mathrm{CHI}$ & 0,1405 & $\mathrm{R} \$$ & 0,73 & $\mathrm{R} \$$ & 0,10 \\
\hline & TOTAL $(R \$ / M 3)$ & & & & & $\mathbf{R} \$$ & 60,13 \\
\hline
\end{tabular}


Revista Multidisciplinar do Nordeste Mineiro, v.2 2021/02

ISSN 2178-6925

Fonte: SINAPI 


\section{RESULTADOS E DISCUSSÃO}

O propósito do presente trabalho foi analisar financeiramente e, contrapor dois tipos de pavimentação, a pavimentação flexível (asfáltica) e pavimentação rígida (blocos de concretos intertravado). A análise foi realizada no empreendimento Macatuba, construção essa destinada para casas populares. Além de valores, podemos apontar também possíveis problemas e melhorias que cada um dos tipos de pavimentação poderia nos acarretar a escolha.

Tabela 3: Comparação total de valores

\begin{tabular}{|c|c|c|c|c|c|}
\hline Serviço & Unidade & $\begin{array}{l}\text { Área de } \\
\text { Execução }\end{array}$ & \multicolumn{2}{|c|}{$\mathrm{R} \$ / \mathrm{M} 3$} & Total \\
\hline EXECUÇÃO DE PAVIMENTO COM APLICAÇÃO DE CONCRETOASFÁLTICO, CAMADA & M3 & $17.013,41$ & $\mathrm{R} \$$ & $64,25 \mathrm{R} \$$ & $1.093 .111,59$ \\
\hline 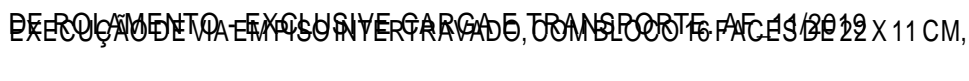 & M3 & $17.013,41$ & $\mathrm{R} \$$ & $60,13 \mathrm{R} \$$ & $1.023 .016,34$ \\
\hline
\end{tabular}

ESPESSURA 8 CM. AF_12/2015

\section{Fonte: Autoria Própria}

Após estudo dos orçamentos fornecidos pela tabela SINAPI, e dimensões das vias de execução fornecidas pelo projeto, encontrou-se o valor por $\mathrm{m}^{2}$ de $\mathrm{R} \$ 64,25$ para o pavimento asfáltico e o valor por $\mathrm{m}^{2}$ de $\mathrm{R} \$ 60,13$ para os blocos intertravados, assim tendo os valores finais de $\mathrm{R} \$ 1.093 .111,59$ para o pavimento asfáltico e $\mathrm{R} \$ 1.023 .016,34$ para o pavimento de bloco intertravado, uma diferença de $\mathrm{R} \$ 70.095,25$ entre os dois tipos, valor esse que corresponde a $6,41 \%$ de acréscimo utilizando os blocos intertravados.

Dessa forma, analisando apenas o desembolso financeiro na construção, temos como melhor alternativa econômica o pavimento asfáltico CBUQ, mas, como evidenciado anteriormente devemos levar em conta os pontos fortes de cada tipo antes da tomada de decisão final. Podemos citar também para a comparação o tipo de instalação, vida útil do material escolhido, reforma, permeabilidade etc.

Pesquisando sobre a vida útil dos pavimentos, o bloco de concreto intertravado acaba sendo a alternativa número um, já que, a vida útil do pavimento asfáltico tem no máximo 12 anos até a sua perca, já o pavimento intertravado bem executado e aplicado tem 20 anos de vida útil, quase $40 \%$ a mais que o pavimento asfáltico, após aplicação, podemos comparar também a manutenção dos pavimentos. Mais uma vez o bloco intertravado se sobressai ao confrontar com o CBUQ, quando um problema na pavimentação é encontrado, a forma de resolução do intertravado é muito mais 
Revista Multidisciplinar do Nordeste Mineiro, v.2 2021/02

ISSN 2178-6925

simples que o asfalto, o custo da operação é menor, já que na maioria dos casos não 
há necessidade de troca de grandes quantidades de bloco, até os blocos danificados podem ser reaproveitados em outras operações de reparo, diferente do pavimento asfáltico que necessita de um novo material para sua produção, sem contar que o tempo impacta bastante na execução, o pavimento asfáltico necessita de prazo alongado na restauração, pois seguem-se maiores etapas de execução.

Partindo para o balanço entre os pavimentos no impacto ambiental, o pavimento de concreto intertravado mais uma vez vence em comparação a pavimentação asfáltica, o ponto que podemos melhor avaliar é a absorção de água principalmente pluvial para os lençóis freáticos. O asfalto é conhecido por sua impermeabilidade, diferente dos blocos intertravados que também são chamados de pisos drenantes. Quando a produção do intertravado não leva em consideração sua drenagem por si só, a água é absorvida pelas juntas entre os blocos, assim oferecendo uma absorção da lâmina d’água.

Dentre os pontos abordados, a utilização de bloco de concreto intertravado é a melhor opção para o empreendimento em questão.

\section{CONCLUSÃO}

O pavimento é extremamente notável nos meios urbanos, sendo sinônimo de conforto e segurança à população. A busca pela pavimentação ideal é continua no setor da engenharia, onde se dedica moderar custos e manutenção. A análise intrínseca do atual estudo é o menor custo de execução de cada tipo, não descartando o estudo da execução, trafegabilidade e possíveis danos ao meio ambiente.

Dessa forma, o trabalho apresenta a possibilidade do emprego dos dois tipos de revestimento, sendo eles praticáveis, já que suas distinções presenciadas sendo na própria estrutura, como em seus valores, são proporcionalmente satisfeitas com uma excelente gerencia de engenharia ao longo da empresa que o executará.

Podemos concluir que ao analisar o custo do empreendimento, a pavimentação asfáltica é o melhor caminho, já que, são mais baratos comparados aos blocos intertravados. Já para os demais parâmetros, sendo eles, manutenção, vida útil e percolação da água retornando ao subsolo, a melhor alternativa seria os blocos intertravados.

Assim, para o empreendimento residencial apontado, é indicado o uso e aplicação do pavimento de blocos de concreto intertravados, sendo capaz como saída possível a pavimentação asfáltica, quando a realização dele se tornar impraticável. 
Revista Multidisciplinar do Nordeste Mineiro, v.2 $2021 / 02$

ISSN 2178-6925

Mesmo o bloco intertravado de concreto sendo $6,41 \%$ mais onerosos em sua 
execução, no decorrer dos anos e sua vida útil será superior e, suas manutenções serão mais fáceis e de baixo custo. Vale ressaltar também o impacto ambiental reduzido com os blocos intertravados.

Conclui-se além que, a partir do atual estudo é capaz de conceber os custos do bloco intertravado e revelar a sensatez coletiva de que ele a todo momento gera custos de execução muito maiores que a pavimentação asfáltica, excluindo de pronto a utilização dos blocos. Desse modo, a exequibilidade do bloco intertravado é completamente aceitável, pois sua longevidade e fácil manutenção são superiores ao comparar com o pavimento asfáltico. Comprovando uma boa alternativa de custo a longo prazo.

\section{REFERÊNCIAS BIBLIOGRÁFICAS}

ABNT. ASSOCIAÇÃO BRASILEIRA DE NORMAS TÉCNICA. NBR 16416 Pavimentos permeáveis - Requisitos e Procedimentos. Rio de Janeiro, 2015.

ASSOCIAÇÃO BRASILEIRA DE CIMENTO PORTLAND. ET-27. Pavimentação com peças pré-moldadas de concreto. 4a ed. São Paulo. 1999.

ASSOCIAÇÃO BRASILEIRA DE CIMENTO PORTLAND. Manual de Pavimento Intertravado: Passeio Público. 1a ed. São Paulo. 2010.

AUGUSTO JUNIOR, F. Manual de pavimentação urbana. São Paulo: Instituto de Pesquisas Tecnológicas (IPT), 1992.

BERNUCCI et al., Liedi B. Pavimentação asfáltica: formação básica para engenheiros. Rio de Janeiro: Petrobrás - Abeda, 2007.

CARVALHO, Marcos D. Pavimentação com peças pré-moldadas de concreto (ET27). Associação Brasileira de Cimento Portland (ABCP) (ET-27). São Paulo, 1998. $53 p$.

DEPARTAMENTO NACIONAL DE INFRAESTRUTURA (DNIT). Manual de Pavimentação. 3. ed. Rio de Janeiro: Ministério dos Transportes - DNER. Instituto de Pesquisas Rodoviárias, 2006. 
FERREIRA, Romário. Pavimento intertravado de concreto x pavimento asfáltico. PINI, São Paulo/SP, dez. Edição 125.

KNAPTON, J. Romans and their rodas. The original small element pavement technologists. In: FIFTH INTERNATIONAL CONCRETE BLOCKS PAVING CONFERENCE, 5, Tel-Aviv, Israel, 1996, p. 17-52.

MULLER, R. M. Avaliação de transmissão de esforços em pavimentos intertravados de blocos de concreto. 2005. Tese (Mestrado em Engenharia Civil). UNIVERSIDADE FEDERAL DO RIO DE JANEIRO, Rio de Janeiro, 234f.

NAKAMURA, J. Pavimentação asfáltica. Revista Infraestrutura Urbana. Editora Pini. Edição n.16. São Paulo, 2011.

OLIVEIRA, Cinara Souza de Análise Comparativa técnico-econômica entre os pavimentos de concreto asfáltico e blocos intertravados de concreto; 2018.

SANTANA, Humberto. A filosofia dos calçamentos na pavimentação urbana. In: REUNIÃO DE PAVIMENTAÇÃO URBANA DA ASSOCIAÇÃO BRASILEIRA DE PAVIMENTAÇÃO, 4. Maceió: ABPv, 1993.

SENÇO, Wlastermilerde. Manual de técnicas de pavimentação. V. 1, 2. ed. São Paulo: Pini, 2007.

SHACKEL, B. (1979). "A pilot study of the performance of block paving under traffic using a heavy vehicle simulator". In: SYMPOSIUM ON PRECAST CONCRETE PAVING BLOCK, Johannesburg. Proceedings. s.l., Concrete Society of Southern Africa Concrete Masonry Association, s.d.

WIEBBELING, P.O.G. Pavimento com blocos intertravados de concreto estudo de casos na Univates. 2015. Monografia (Trabalho de conclusão curso de Engenharia Civil) Centro Universitário Univates. Lajeado. 
Faculdade Presidente Antônio Carlos de Teófilo Otoni

FICHA DE ACOMPANHAMENTO INDIVIDUAL DE ORIENTAÇÃO DE TCC

Atividade: Trabalho de Conclusão de Curso- Artigo/ Monografia.

Curso: Engenharia Civil Período: $10^{\circ}$ Semestre: $2^{\circ}$ Ano: 2020

Professor (a): Augusto dos Santos Petzold

Acadêmico (s): José Alves Pereira Neto/ Vinicius Almeida de Barros

Tema:

Uso de vedações alternativas na construção civil.

Assinatura do aluno José Neto

Vinicius Almeida

\begin{tabular}{|c|c|c|c|}
\hline Data(s) do(s) atendimento(s) & Horário(s) & & \& \\
\hline $26 / 08 / 2020$ & $08: 00-09: 00$ & $\pi$ & \\
\hline $27 / 08 / 2020$ & $11: 00-12: 00$ & $m$ & \\
\hline $25 / 09 / 2020$ & $11: 00-12: 00$ & की & H \\
\hline $02 / 11 / 2020$ & $19: 00-20: 00$ & 92 & \\
\hline $05 / 11 / 2020$ & $15: 00-16: 00$ & tel & 7 \\
\hline
\end{tabular}

Considerando a concordância com o trabalho realizado sob minha orientação, AUTORIZO O DEPOSITO do Trabalho de Conclusão de Curso do (a) acadêmico (a) com titulo: Analise final da pesquisa derradeira.

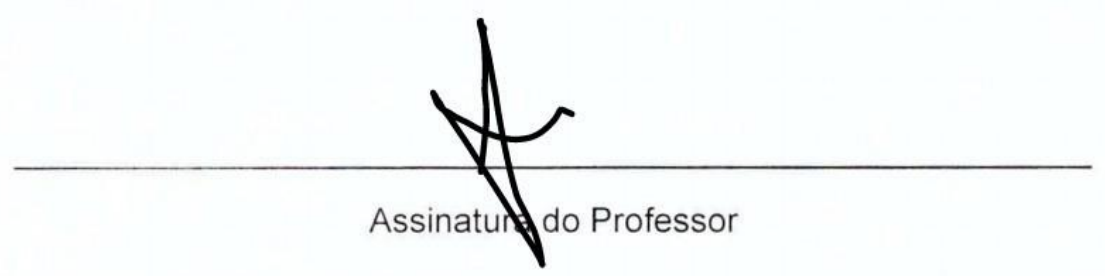


Revista Multidisciplinar do Nordeste Mineiro, v.2 2021/02

ISSN 2178-6925

CopySpider

nttps://copyspider.com.br/

Relatório gerado por: neto.joseap@gmail.com

\section{Arquivos}

Termos comuns Similaridade

TCC_Analise_Comparativa_Do_Custo_Beneficio_Entre_Pavim 204

entação_Asfáltica.docx X

http://www.anpet.org.br/anais/documentos/2019/Infraestrutura/

Dimensionamento, Avaliação e Gestão de Pavimentos

III/1_719_AC.pdf

TCC_Analise_Comparativa_Do_Custo_Beneficio_Entre_Pavim

entação_Asfáltica.docx X

3

0,06

https://ptitwikipedia.org/wiki/Universidade_Presidente_Antônio_

Carlos

TCC_Analise_Comparativa_Do_Custo_Beneficio_Entre_Pavim

0

entação_Asfáltica.docx X

https://www.reference.com/world-view/firm-economics-

$1 \mathrm{e} 6611 \mathrm{a} 186 \mathrm{e} 19 \mathrm{~d} 0 \mathrm{~b} ? \mathrm{ad}=\mathrm{dirN} \& q \mathrm{O}=$ serplndex\&o=740005

TCC_Analise Comparativa_Do_Custo_Beneficio_Entre_Pavim - Download falhou. HTTP response code: entação Asfáltica.docx $\mathrm{X}$ https://www.fastcompany.com/38406/its-your-choice

TCC_Analise_Comparativa_Do_Custo_Beneficio_Entre_Pavim - www.fastcompany.com entação_Asfáltica.docx X

https://www.lifehack.org/articles/lifehack/making-quick-choices-

to-manage-time-better.html

TCC_Analise_Comparativa_Do_Custo_Beneficio_Entre_Pavim - Download falhou. HTTP response code: entação_Asfáltica.docx $\mathrm{X}$

https://www.sciencedirect.com/topics/engineering/asphalt-

pavements

TCC_Analise_Comparativa_Do_Custo_Beneficio_Entre_Pavim

0

entação Asfáltica.docx X

https://bizfluent.com/13662860/facts-on-economics

TCC_Analise_Comparativa_Do_Custo_Beneficio_Entre_Pavim

entação_Asfáltica.docx $X$

https://www.life123.com/article/why-plus-size-doesnt-have-to-

mean-less-choice?ad=dirN\&qo=serplndex\&o=740009

TCC_Analise_Comparativa_Do_Custo_Beneficio_Entre_Pavim

entação_Asfáltica.docx $X$

- www.sciencedirect.com

https://www.geteducated.com/online-schools/blinn-college/as-

in-economics

TCC_Analise_Comparativa_Do_Custo_Beneficio_Entre_Pavim

entação_Asfáltica.docx X

https://www.elledecor.com/design-decorate/a947/multiple-

choice-17449 


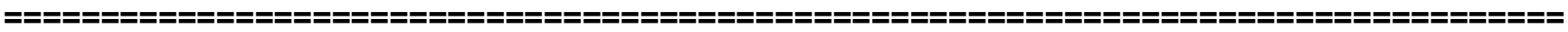

Arquivo 1: TCC_Analise_Comparativa_Do_Custo_Beneficio_Entre_Pavimentação_Asfáltica.docx (3549 termos)

Arquivo 2: http://www.anpet.org.br/anais/documentos/2019/Infraestrutura/Dimensionamento, Avaliação e Gestão de Pavimentos III/1_719_AC.pdf (3911 termos)

Termos comuns: 204

Similaridade: $2,81 \%$

O texto abaixo é o conteúdo do documento

TCC_Analise_Comparativa_Do_Custo_Beneficio_Entre_Pavimentação_Asfáltica.docx.Os termos em vermelho foram encontrados no documento

http://www.anpet.org.br/anais/documentos/2019/Infraestrutura/Dimensionamento, Avaliação e Gestão de Pavimentos III/1_719_AC.pdf

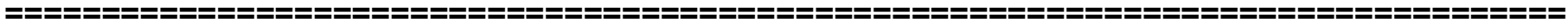

ANÁLISE COMPARATIVA DO CUSTO-BENEFÍCIO ENTRE PAVIMENTAÇÃO ASFÁLTICA E A COM BLOCOS INTERTRAVADOS DE CONCRETO

\section{COMPARATIVE COST-BENEFIT ANALYSIS BETWEEN ASPHALT PAVING AND BLOCKS CONCRETE INTERLOCKED}

Vinicius Almeida de Barros

Graduando, Faculdade Presidente Antônio Carlos, Brasil.

E-mail: viniciussalmeidaa13@gmail.com

Jose Alves Pereira Neto

Graduando, Faculdade Presidente Antônio Carlos, Brasil.

E-mail: neto.joseap@gmail.com

Augusto Petzold

Mestre, Faculdade Presidente Antônio Carlos, Brasil.

E-mail: augustopetzold2014@gmail.com

\section{RESUMO}

Este trabalho tem como objetivo comparar economicamente o pavimento asfáltico executado no sistema viário do "Empreendimento Macatuba" localizado na cidade de Macatuba-SP e o pavimento intertravado como alternativa de pavimentação. Durante a revisão da literatura buscou-se a descrição do processo de pavimentação, referencial histórico, assim como, seu processo executivo, dando ênfase aos conceitos associados a pavimentos intertravados e os pavimentos asfálticos, destacando suas vantagens e desvantagens em relação à escolha do melhor tipo de pavimento viário. Foi dimensionado o pavimento intertravado e realizado a comparação estrutural com o pavimento asfáltico. De posse dos quantitativos obtidos das estruturas dos dois pavimentos foram elaborados os respectivos orçamentos através da tabela SINAPI para a comparação dos custos. Ao final, coloca-se a partir dos resultados alcançados no trabalho , a viabilidade técnica e econômica da implantação do bloco intertravado como solução ao sistema viário 